\title{
MITO Y POÉTICA EN TORNO A LA REESCRITURA EVA PERón EN LA Hoguera (1972) DE LEÓNIDAS LAMBORGHINI
}

\author{
Lorena Pontelli \\ Universidad Nacional de Rosario \\ Consejo Nacional de Investigaciones Científicas y Técnicas \\ lorepontelli@gmail.com
}

Resumen: Nuestro objetivo en las siguientes páginas es reflexionar en torno a la relación entre mito y poética como estrategia específica de producción de sentido. Con este fin, abordaremos la reescritura de Leónidas Lamborghini, Eva Perón en la hoguera (1972), acerca del libro La razón de mi vida (1951) de Eva Perón. Vamos a concebir a la operatoria lamborghineana como un movimiento de solicitación que se sitúa en esta estructura del mito para reconocer desde él mismo su propia estrategia, sus intereses, y los límites de su actividad en el tiempo. En otras palabras, tomaremos a la reescritura como una política del lenguaje y como una suerte de estrategia o metodología del desciframiento del mito (Modelo), tarea que se realiza a partir de la sintaxis y la escucha del ritmo.

Palabras clave: Leónidas Lamborghini, Poesía, Mito, Eva Perón.

\begin{abstract}
Our objective in the following pages is to reflect on the relationship between myth and poetics as a specific strategy for the production of sense. To this end, we will address the rewriting of Leónidas Lamborghini, Eva Perón en la hoguera (1972), about the book The reason for my life (1951) by Eva Perón. We are going to conceive of the lamborghinian operatory as a movement of solicitation that is situated in this structure of the myth to recognize from itself its own strategy, its interests, and the limits of its activity in time. In other words, we will take rewriting as a politic of language and as a kind of strategy or methodology for deciphering the myth (Model), a task that is carried out from the syntax and listening to the rhythm.
\end{abstract}

Keywords: Leónidas Lamborghini, Poetry, Myth, Eva Perón. 


\section{Introducción}

Pensar Leónidas Lamborghini en este artículo tiene el propósito de insistir en un acto de solicitud. Solicitar es, como decía Jacques Derrida (1998), sacudir como un todo el lenguaje, hacer temblar el edificio de signos que gobiernan el habla: "gobernar es hablar/es poblar" (Lamborghini, 2008, p. 24). Este acto de solicitud implica un movimiento, un deambular por los márgenes de la lengua como denuncia de esa inconsistencia de los discursos dominantes (el del canon literario argentino, el de la poesía heroica peronista). Un vagabundeo que en su andar aporético trasluce lo indecidible e inacabado del signo, lo que violentamente no fue contado y, por lo tanto, lo por-venir. Pensar Lamborghini es situarse en las guerras del lenguaje, en la política como lucha por la significación. Pero también, al decir de Henri Meschonnic, es preguntarse spinozianamente "qué puede un cuerpo en el lenguaje" (2007, p. 31). La poética de Leónidas Lamborghini ahonda sin anestesias previas la relación entre las palabras y el dolor. En ella, el afecto emerge como razón poética: ya no hay metáforas que nos envuelvan y alivianen la aflicción. Ese dolor que "es siempre plural (de una clase social, un partido, de una fracción, de una nación) y lo convierte en íntimo" (Prieto, 2008, p. 233). Pensar Lamborghini es adentrarse en una escritura que surge "desde la herida que sangra" (Friedemberg, 1999, p. 154), y que hace de esta una táctica que no esconde su intento de historicidad. El estilo de Lamboghini permite pensar la poesía como el ocaso de la metáfora y del logocentrismo de "lo bello" que hábilmente evade la vida y la finitud. 
Nuestro objetivo en las siguientes páginas es reflexionar en torno a la relación entre mito y poética, para pensarla como una ética y una política, una estrategia específica de organización de la representación y producción de sentido. Con este fin, abordaremos la reescritura de Leónidas Lamborghini, Eva Perón en la hoguera (2011), publicado por primera vez en 1972, acerca del libro La razón de mi vida (1951) de Eva Perón. Partimos de comprender a este último texto como un "organismo moral" (González, 2008) que forma parte del mito peronista. Vamos a concebir a la operatoria lamborghineana no como una forma de salir del mito sabemos que es imposible- sino como un movimiento de solicitación que se sitúa en el mito para reconocer desde él mismo su propia estrategia, sus intereses, y los límites de su actividad en el tiempo. En otras palabras, tomaremos a la reescritura como una política del lenguaje (como la piensa el mismo Lamborghini) y como una suerte de estrategia o metodología del desciframiento del mito (Modelo) que se hace no ya desde la observación de relación entre el significante y el significado, sino desde la sintaxis y la escucha del ritmo. Intentaremos analizar poéticamente el mito y los sentidos que, desde la reescritura Lamborghini, productivamente emergen en la capilaridad del texto.

Hemos decidido dividir este trabajo en dos partes. En un primer momento — "La razón de mi vida como organismo moral del mito"- comenzaremos por hacer un somero recorrido del concepto de mito en distintos autores del siglo $\mathrm{XX}$; posteriormente, abordaremos la relación que establece Carlos Astrada entre el mito y la poesía en su obra El mito 
gaucho para pensarla en términos de antecedente de nuestro tema; y concluiremos con una justificación de la elección de La razón de mi vida como elemento a trabajar mitopoéticamente. En un segundo momento, titulado "La reescritura Eva Perón en la hoguera de Leónidas Lamborghini”, hablaremos por un lado, de la metamorfosis mítica que produce la reescritura, que es también la metamorfosis del lenguaje, y la función que cumple la hoguera en la poesía. Por otro lado, analizaremos la reescritura lamborghineana como una poética que nos devuelve al primer momento de la lengua, cuando lo simbolizable empieza a emerger. Para ello nos valdremos de los conceptos de ritmo tanto de Julia Kristeva (1984) y de Meschonnic (2007), como también la noción de materialismo ensoñado de León Rozitchner (2011).

\section{La razón de mi vida como organismo moral del mito}

I.

Aunque durante tiempos los cancerberos del discurso realista han tratado de conjurar al pensamiento mítico, este no ha dejado de asediar e insistir en los bordes de la filosofía política. A continuación, trazaremos una serie de apuntes breves, para señalar someramente cómo algunos pensadores del siglo XX han comprendido el valor heurístico que tiene el mito para intentar pensar las complejidades de nuestro tiempo común. 
A principios del siglo XX el mito resurge con ímpetu desde las teorizaciones de Jean Sorel. En Reflexiones sobre la Violencia (1905-1907) define a la "huelga general proletaria" como un mito, es decir, como "una organización de imágenes capaces de evocar instintivamente todos los sentimientos que corresponden a las distintas manifestaciones de la guerra emprendidas por el socialismo contra la sociedad moderna" (Sorel, 1979, p. 129). El mito se vuelve entonces un conocimiento inmanentemente verdadero, capaz de explicitar la conciencia de clase. Esta concepción es retomada por otro pensador marxista, Antonio Gramsci, quien en el escrito El principe moderno (1932) afirma que El Príncipe (1513) de Maquiavelo debe ser pensado como un ejemplo histórico del mito soreliano $y$, traslada esta idea al partido político, concibiéndolo como un príncipe moderno, un mito-príncipe. ${ }^{1}$

En Nuestra América, José Carlos Mariátegui en su breve ensayo "El hombre y el mito" (1925) reconoce que el pensamiento mítico tiene la fuerza de aglutinar voluntades colectivas y darles un sentido histórico a los pueblos. Afirma que la revolución moderna se sustenta sobre el mito de la libertad, aunque este haya sido sacrificado por la misma burguesía en pos de la persecución de propios intereses:

\footnotetext{
1 'El príncipe moderno, el mito-príncipe no puede ser una persona real, un individuo concreto; sólo puede ser un organismo, un elemento de la sociedad complejo en la que ya se haya iniciado la concreción de una voluntad colectiva reconocida y afirmada parcialmente en la acción. Este organismo ha sido creado ya por el desarrollo histórico: es el partido político, la primera célula en la que se reúne unos gérmenes de voluntad colectiva que tienden a convertirse en universales y totales" (Gramsci, 1993, p. 67).
} 
Lo que más neta y claramente diferencia en esta época a la burguesía y al proletariado es el mito. La burguesía no tiene ya mito alguno. Se ha vuelto incrédula, escéptica, nihilista. El mito liberal renacentista, ha envejecido demasiado. El proletariado tiene un mito: la revolución social (Mariátegui, 1987, p. 23).

Es interesante contrastar la tesis de Mariátegui con las definiciones que surgirán en torno al mito durante la posguerra, principalmente desde el estructuralismo con Barthes como portavoz. En sus Mitologías (1957), el autor francés rechaza la posibilidad de que el mito pueda ser pensado en consonancia con la política, entendida como praxis revolucionaria o construcción colectiva. Bastante cercano a la conceptualización que posteriormente hará Althusser (2005) en torno a la ideología, el mito para Barthes es despolitizante, aparece como una estructura representativa con una lógica de interpelación especular que media entre el sujeto y las reales condiciones del orden burgués. Barthes sostiene que es un uso social, un habla que, si bien finge bajo una economía de los enunciados surgir "naturalmente" desde las cosas — de ahí su efecto despolitizante- "es la historia la que hace pasar lo real al estado de habla" (Barthes, 2014, p. 200) y por lo tanto solo puede tener un fundamento histórico.

Sin embargo, aunque no compartimos el carácter despolitizante del mito, consideramos que ciertos aspectos del análisis barthesiano muestran una potencialidad analítica a tener en cuenta. Dirá que todo lo decible puede ser un mito porque el mito es un habla, un modo de significación, una 
forma que no se define por su contenido o sustancia. El mito es un metalenguaje, una lengua que habla sobre la lengua (mito $=$ signo [significante/significado] + significado), para decirlo en palabras de González: "En un extremo, todo lenguaje es mítico, aunque conviene llamar mito solo al procedimiento por el cual parece que hablamos de la realidad, pero en verdad hablamos del lenguaje que habla de la realidad" (2012, p. 167).

Barthes señala que existe una paradoja a la hora de pensar la apuesta de significación mítica: "el mito no oculta nada, su función es la de deformar, no la de desaparecer" (2014, p. 213). No por mera casualidad, pero sí con una leve sorpresa, esta definición de Barthes nos ayuda a mantener presente nuestro propósito de pensar Lamborghini. En el año 1989, Jorge Fondebrider entrevista al autor de El Solicitante Descolocado, y la entrevista es titulada como "Las intenciones son enormes; los resultados, deformes" (Fondebrider, 1994), frase que Lamborghini desliza para explicar el proceso de reescritura. Más tarde, ahondaremos en este tema, pero lo que es importante aquí retener es la relación que implícitamente podemos establecer entre el mito y la reescritura. Una vez más, afirmamos que la reescritura no es un mecanismo que actúa contra el mito, ni intenta salir de él. Para decirlo de otro modo, si entendemos que la reescritura es una estrategia de representación del lenguaje mismo, entonces la reescritura es explícitamente mito.

Retomando nuestra modesta historización del pensamiento mítico, a diferencia de Barthes, para quien en última instancia el mito actuaba como un relato con pretensiones de universalidad pero que en realidad escondía sus condiciones de 
producción y no representaba más que los valores ideológicos, políticos y culturales de la burguesía; Lévi-Strauss (1997) dirá que el pensamiento mítico es la forma de pensamiento primero. En este texto, sin dejar de lado los valiosos aportes ya nombrados, partimos de la definición de mito del autor del Pensamiento salvaje.

Para Lévi-Strauss el mito es una estructura permanente de la lengua, que ha funcionado en todas las épocas y pueblos como un particular sistema de comunicación, con sus propios códigos. Sostendrá que lengua y habla no son lo mismo. La lengua es una estructura omnipresente (es decir, que no tiene historia, como el inconsciente para Freud o la ideología en general para Althusser) mientras que sí se puede rastrear una historia en el habla, en las narraciones producto de contingencias que cada agrupación humana ha creado y que por eso son diacrónicas. Sin embargo, lo que a Lévi-Strauss le interesa es analizar las estructuras sincrónicas —la lengua-, aquellas que a pesar de ser dinámicas son estables a lo largo del tiempo, como el mito.

Puede decirse que el mito tiene dos niveles, el habla (la narración) y la lengua (estructura lingüística, combinación de metáforas y metonimias). La producción de sentido depende de la articulación de estos dos niveles. Para Lévi-Strauss, el valor del mito es "el de preservar en forma residual modos de observación y reflexión que estuvieron (y siguen estando sin duda) exactamente adaptados a descubrimientos de un cierto tipo: los que autorizaba la naturaleza, a partir de la organización y de la explotación del mundo" (Lévi-Strauss, 1997, p. 35). En El pensamiento salvaje (1962), dicho autor 
designa a la actividad del pensamiento mítico como un bricolage, que evoca movimientos accidentales o ingenuos para crear nuevas estructuras de pensamiento que den cuenta de acontecimientos naturales e históricos. Lo propio del bricolage es que instrumentalmente apuesta a un "arreglárselas con lo que se tiene", siendo consciente de la finitud de materiales y herramientas de las que dispone y de las limitaciones de sentido que los elementos del lenguaje que el mito toma prestados llevan consigo. "El conjunto de medios del bricoleur [...] se definen solamente por su instrumentalidad [...] en razón del principio de que 'de algo habrán de servir"' (Lévi-Strauss, 1997, p. 37). Es en este sentido que el autor entrelaza el pensamiento mítico con la creación poética, el bricolage es una suerte de poesía que "construye palacios ideológicos con los escombros de un antiguo discurso social" (Lévi-Strauss, 1997, p. 43). Es una estructura que permite producir un nuevo objeto/estructura en cuyo interior habitan un conjunto de acontecimientos, por lo tanto, todo mito cuenta una historia (mito $=$ objeto + acontecimiento). Es por esto que el mito es muy productivo en términos políticos. En su lógica reidentificatoria despojada de historicidad y territorialización, tiene el efecto de poder juntar lo irreconciliable. El mito puede desarrollar una función básicamente regeneradora de lo comunitario, por su capacidad de integrar en un mismo tipo de práctica ritualizada lo sagrado y lo profano; lo instituido y lo ausente, devolviendo lo comunitario al grado cero de lo simbolizable. 


\section{II.}

Entre las plumas rioplatenses que han rescatado al mito como modelo heurístico se encuentran las de Leopoldo Lugones y Carlos Astrada. Graciela Ferràs (2007) señala que la obra de Lugones, Prometeo (un proscripto del sol) del año 1910, dialoga con la filosofía del pensamiento mítico, entrelazando los valores de la Ilustración con una pedagogía de la "estética de la nacionalidad”. Dice Lugones (1910):

[...] en el fondo y primordialmente, una alegoría de la ley de causalidad que engendra la periodicidad eterna de todos los fenómenos. Así puede repetirse y se repite el mito en una serie de fenómenos análogos; pero no en el mismo fenómeno como lo quiere la ciencia actual (citado en Ferràs, 2007).

Para Fèrras, contrariamente a otras interpretaciones de los escritos lugonianos, esta es una invitación a pensar la "filosofía de la transformación", entendiendo al mito como aquello que sobrevive a la corrosión del tiempo, pero sin excluir la posibilidad de la transfiguración.

Por su parte, Carlos Astrada en el Mito Gaucho (1948) intenta reconstruir un proyecto de identidad nacional a partir del Martín Fierro de José Hernández. La obra de Hernández es pensada por Astrada como un mitopoema capaz de recrear y movilizar a un sujeto histórico, en contraste entonces con las conceptualizaciones estructuralistas de Levi-Strauss y Barthes ya mencionadas. Astrada exhorta a poner el oído en la tierra, para descubrir en la respiración de lo telúrico como Anaké, el llamado del "destino gaucho" -un destino trashumante y con 
restos de beduino- que emana de la pampa. Le interesa hallar la esencia del "ser nacional" en el gaucho, pero reconociendo que su unidad inevitable y necesariamente será híbrida. La composición de este hibridismo del gaucho lleva en sí la marca de la matriz de acumulación colonial, y resulta de la reunión de los sujetos subalternos del Sur: los negros y los indios. Es sumamente interesante el concepto de hibridismo que utiliza Astrada, como forma de entender la no supresión de las particularidades de estas otredades que se incluyen bajo el significante gaucho sin borrarse ('icomo mezcolanza!' diría Lamborghini). Pero lo nacional como particularidad debe integrarse con lo universal. Por lo tanto, reconoce en las hibridaciones del gaucho, un pasado previo de árabe (de los que los pampeanos heredaremos la extensión del desierto en nuestro interior y la cultura del silencio, pulso que recorre los cancioneros de nuestro folclore) y andaluz, haciendo que el destino de "los hijos de Fierro" -las masas peronistas- sea universal. Al analizar la etimología de la palabra "gaucho", Astrada llega a la conclusión de que este término significa finalmente "conductor de ganado". ${ }^{2}$ Creyó ver en Perón el líder capaz de captar y conducir el espíritu del pueblo

\footnotetext{
${ }^{2}$ No podremos adentrarnos mucho en esta idea, nos contentamos con señalar relación que Foucault ya planteó entre la idea de pastoreo y del gobierno de los hombres. También es bastante explícita la conjugación de este significado dado por Astrada a su sujeto político, con el del líder del peronismo, Juan Domingo Perón. En el I Congreso Nacional de Filosofía de la Argentina (1949), luego de la publicación de El Mito Gaucho, Astrada es uno de los participantes principales, y es también el escenario en el que Perón expone su famosa conferencia "La comunidad organizada". Este acontecimiento político para Donnantuoni Moratto (2009) significa la constelación de los dos andamiajes teóricos más importantes que sostendrán a la doctrina de la Tercera Posición: el mito gaucho y La comunidad organizada.
} 
argentino, pero estas esperanzas son canceladas ya en la segunda edición del libro (1964), cuando Astrada elimina toda alusión al movimiento peronista y, peor aún, denosta a Perón representándolo como el Viejo Vizcacha.

Una de las particularidades del concepto de mito que Astrada expone, desde nuestro punto de vista, es que intenta reconciliarlo con el pensamiento dialéctico hegeliano (acción que se puede vislumbrar en este juego de lo nacional-universal, particularidad-totalidad) para hacer de él un proyecto político: el de una "gauchocracia comunitaria" que se proponga la lucha por la liberación nacional del extranjero y un régimen social justo (Astrada, 1964). Creemos que en este propósito de crear "una meta histórica conceptualizada", al citar a George Gusdorf quien apunta: "Los pueblos fuertes poseen confianza en sus mitos; bien demostrativo de ello es el ejemplo de Rusia y el de Estados Unidos" (Astrada, 1964, p. 44), puede entreverse cierta evocación a una suerte de voluntad de poder de los pueblos.

No obstante, lo que más nos interesa en este escrito es la relación que el filósofo establece entre el mito y el poema:

Es el mito vivo [en referencia al Martín Fierro] y prospectivo que, por cuanto es un retornar al origen, a la fluencia misma del manantial, pone ante nuestros ojos los lineamientos del posible devenir de un estilo gentilicio en el ámbito de nuestro genius loci pampeano. Este mito no es una creación imaginativa, sino una realidad en el proceso, pero interferida, asediada por factores negativos, los que solo pueden ser eliminados por la fuerza ínsita en el mito mismo [...]; el mitologema en este caso se revela poéticamente, y tenemos conciencia de que él es algo 
real (...) Lo real del mito acude, para su expresión al logos poético. El mito, en el sentido en que lo tomamos, no es identificable con lo poético; lo poético es su expresión. Karl Kerényi establece claramente esta diferencia. El mito, 'la mitología, es una especie de poemática, pero no en estricto sentido. Ella penetra solo en la poesía. Grandes poetas fueron los más competentes relatores de mitos' (Astrada, 1964, pp. 42-43, el destacado es nuestro).

Nos parece que existen algunos puntos en común entre el planteo de Astrada y su maestro Heidegger, cuando en su ensayo Hölderin y la esencia de la poesía (1936) decía que el hombre es aquel que manifiesta su existencia $y$, al hacerlo, manifiesta la pertenencia a la intimidad (que reúne aquellas cosas en conflicto que están separadas) (Heidegger, 1992). La manifestación de la pertenencia a esta intimidad acontece mediante la creación de un mundo, que Vattimo define como "un horizonte-contexto que se revela como un sistema de significados" (1992, p. 67). Encontramos en la definición de Vattimo cierta cercanía con uno de los rasgos del pensamiento astradeano, el mito como "meta histórica conceptualizada". Por lo tanto y parafraseando a Heidegger, podríamos conjeturar que el mito sería, para Astrada, la manifestación de la existencia que se vuelve histórica solo cuando el poeta logra salvar del desgarro del tiempo un resto de ella y la detiene en una palabra antes de que caiga en la muerte y eternidad del silencio. Para Heidegger, solo hay mundo donde hay habla, y solo donde rige el mundo hay historia. 
Sorpresivamente puede pensarse que, tanto la concepción de la poesía como el papel del poeta de Leónidas Lamborghini, se tocan en este punto, con las ideas de Heidegger. Para este escritor "la poesía es una recreación del mundo, tiene ese poder" (Lamborghini, 2006). El poeta actúa embistiendo el lenguaje contra sus propios límites extremos. Allí donde las palabras se rompen y el horizonte-contexto como mundo, se expande, el poeta abre y funda el orden de los significados que constituirán el mundo; y esto solo es posible cuando se arranca a las palabras del abismo del silencio.

Si el mito entonces es, para Astrada, realidad en proceso, ¿puede este pensarse en términos demiúrgicos, como potencia creadora originaria que anuda la acción y la palabra, y en ese caso, concebir tanto al poeta como a la poesía como creaciones-creadoras? ¿ $\mathrm{O}$ debemos recordar al rabino de Praga Judá de León cuando luego de seguir los pasos de la hermenéutica sagrada de la cabalá se lamentaba: "por qué di en agregar a la infinita / serie un símbolo más..." (Borges, 2012, p. 47)? Si la potencia creadora reside en el acto de nombrar del poeta, que mediante el orden de una serie de combinaciones gramaticales llega a verse reflejado en los ojos de algún dios creador ¿no son siempre golems los resultados infinitos de esta operación mitopoética, deformidades-lenguaje lejanas al logocentrismo del signo, como reconocía Lamborghini? Por lo tanto: pensar Lamborghini, alejarse del signo. 
III.

Originariamente La razón de mi vida (1951) había surgido de la intención, por parte del periodista español Manuel Penella da Silva, de elaborar una biografía de Eva Perón basándose en una serie de entrevistas. Luego de las sugerencias de Juan Domingo Perón y Raúl Apod (director de la Subsecretaría de informaciones), el resultado fue un texto que se encuentra más cercano a un susurro de confesión o plegaria con tonos radiales que busca crear empatía con el lector que a una biografía en clave historiográfica.

La razón de mi vida está dividida en tres partes: "La causa de mi misión", "Los obreros y mi misión", "Las mujeres y mi misión". Entre sus páginas se resalta la vocación de Eva Perón de darse a las clases populares en frases acompañadas por el verbo "sentir" y los sustantivos "corazón", "alma", "sacrificio". Pero además, el fin último de su accionar tiene sustento en la imagen de un líder: Perón. "Él, que volaba alto y solo como los cóndores" (Perón, 2010, p. 33), "Él, seguro de sí mismo, y yo, únicamente segura de él" (Perón, 2010, p. 12), frente al cual ella no era más que "una humilde mujer del pueblo", "un gorrión" en una inmensa bandada de gorriones.

Valeria Grimber Pla (2013) afirma que La Razón de mi vida tiene un formato hagiográfico, que se basa en una retórica místico-religiosa cristiana que se entrelaza con un discurso político desde la idea de construir simbólicamente a Evita en función de las imágenes de madre-mártir-santa (que confluyen en la explicación de que su muerte temprana finalmente fue un mandato divino y los posteriores intentos de canonización). 
Sin embargo, esta autora hipotetiza que al imbricarse el discurso mítico con el religioso, lo que se pierde es la politización, cancelada en la cristalización de la imagen de Eva como madre-mártir-santa. Aun así, y si bien es cierto que todo pensamiento mítico tiene resultados deshistorizantes, esto no significa que sea necesariamente despolitizante. Más bien, la performatividad que todo discurso político adquiere cuando absorbe partes de alegorías religiosas forma parte de la potencia mítica. No es más que una forma de enunciación que se encuentra en pugna con otras por organizar lo simbólico y reasignar identidades y significaciones a lo real. En este sentido, la apelación a la figura madre-mártir-santa del hijopueblo peronista refunda una "organización social de la ética y de lo político en función de lo religioso" (Meschonnic, 2007, p. 25).

Para Horacio González (2008), a diferencia de Grimber Pla, La razón de mi vida es un texto que funciona como "organismo moral" del mito peronista:

Cuando decimos que los textos son 'organismos morales' nos referimos a la participación en el pensamiento mítico. Pero no hay acto humano sin que se sienta en él el oculto boato de un lenguaje arcaico que se acomoda para resurgir. Ese movimiento de puja es el del mito. [...] La acción es lo que siempre pugna por revelar el turbio depósito lingüístico de rotas memorias humanas. Es lo que lleva a considerar a los textos como 'organismos morales' no porque de ellos obtengamos formas de vida adecuadas, sino porque ellos solo pueden actuar como pedazos extraviados de una totalidad perdida, un texto maestro que existe en la imaginación esperanzada -el mito-, solo para caer en el limo de las acciones reales con el recuerdo de palabras 
alguna vez dichas que pugnan por llamar nuevamente la atención. Ser pronunciadas como si hubieran sido salvadas de un naufragio; eso es hablar, y cuando se lo consigue con autenticidad (es decir, borrando la memoria del uso anterior de esas palabras), el texto se hace cuerpo moral en su condición de haber sido salvado del pasado asfixiante y de actuar como si no hubiera habido otros antes (González, 2008, p. 419).

Por lo tanto, existe una particular afinidad entre la definición de González del mito como habla con el desarrollo teórico de Barthes indicado en las primeras páginas. Además, persiste una suerte de cariz heideggeriano en lo que hace a la Razón de mi vida como "organismo moral" del mito y que podemos percibir en las alusiones a esa dialéctica entre el habla y silencio que no es más que el movimiento ulterior del lenguaje, pero que en el mito se presenta de manera más nítida, un pensamiento que reúne palabras que parecen "ser pronunciadas como si hubieran sido salvadas de un naufragio". También podemos percibir rastros de las nociones de Lévi-Strauss del mito como pensamiento primero, arcaico, que reúne en sí las ruinas de viejos lenguajes y los reactualiza. Como señala el autor de Restos pampeanos, La razón de mi vida es un texto estatal que termina siendo impuesto en la enseñanza primaria a modo de adoctrinamiento, pero que también -como libro de lectura infantil- forma parte de la "arquitectura sentimental" oficial (González, 2008, p. 25). 


\section{La reescritura Eva Perón en la hoguera de Leónidas Lamborghini}

I.

El fuego ha sido un elemento comúnmente asociado con el clamor revolucionario. Bajo este sentido es también invocado en La razón de mi vida:

Cuando la segunda guerra mundial aflojó un poco la influencia de los imperialismos que protegían a la oligarquía entronizada en el gobierno de nuestro país, un grupo de hombres decidió hacer la Revolución que el pueblo deseaba [...] pero después de los primeros encuentros con la dura realidad de las dificultades, la mayoría empezó a repetir lo mismo de otras revoluciones... y 'la Revolución' fue quedando poco a poco en medio de la calle, en el aire del país, en la esperanza del pueblo como algo que todavía era necesario realizar. Sin embargo, entre los gestores de aquel movimiento, un hombre insistía en avanzar por el camino difícil. Yo lo vi aparecer, desde el mirador de mi vieja inquietud interior. Era evidentemente distinto de todos los demás. Otros gritaban 'fuego' y mandaban avanzar. El gritaba 'fuego' y avanzaba él mismo, decidido y tenaz en una sola dirección, sin titubear ante ningún obstáculo. En aquel momento sentí que su grito y su camino eran mi propio grito y mi propio camino. Me puse a su lado [...] (Perón, 2010, p. 12).

Y la reescritura de Lamborghini, en donde Juan Domingo Perón está presente como ausencia:

un día hay:

un maravilloso:

ese fue. 
lo vi desde...

un momento hay:

el encuentro. el comienzo de mí.

en todas las vidas hay:

lo por hacer. la cosa...

un momento: en qué.

el encuentro: en qué.

mi día: fuego. lo vi desde...

ese fue: de mí. en todas las vidas

hay:

lo monótono sin.

el paisaje sin.

lo definitivo que parece sin:

una cree

pero en el fondo no a aquello: un grito.

no a resignarme. por fin llegó. ese fue:

mi día hay

mi maravilloso.

un camino nuevo: lo por hacer. la cosa por. mi revolución.

ese fue. lo vi desde. fuego: un grito

un dia hay.

un momento hay.

un maravilloso hay (Lamborghini, 2011, p. 65)

El fuego y la analogía con la insurrección es un lugar común en los relatos de sublevaciones, convirtiéndose en una suerte de tautología. En Perón, reflejos de una vida (2008), González le dedica algunas a las líneas al fuego en tanto signo impugnado e imputador de sentidos, ya sean los fuegos del incendio de los peronistas a las iglesias en los días previos a los bombardeos de la Plaza de Mayo, como el fuego de los mismos bombardeos. González señala que en la película Gatica, la Plaza de Mayo es representada míticamente, y el fuego aparece como llamarada 
que carcome los símbolos del peronismo onírico: "Lo soñado como presa del fuego. El sueño quemado. El sueño como fuego" (González, 2008, p. 43). El fuego en la película, según el autor, funciona como un mecanismo gramatical que invierte los sentidos.

A riesgo de errar, conjeturamos que en la poesía Eva Perón en la hoguera, el fuego cumple también este papel de "inversión de sentidos" o, mejor dicho, de metamorfosis de sentidos. Si la poética lamborghiniana no intenta salirse del mito, sino representar el lenguaje desde el desmembramiento de sus componentes, la hoguera destella como una reminiscencia de antiguos fuegos que han abrazado a las mujeres revolucionarias. Los fuegos que se escribieron disciplinariamente sobre el cuerpo de aquellas que vieron morir a Juana de Arco/el fuego de la insurrección de Juana de Arco.

Pero la hoguera también es aquello que corroe la sintaxis, la organización del organismo moral que es La razón de mi vida. El fuego que como fulgor ciega a Eva (ya no la madre-mártirsanta) que al entregarse a la hoguera, se entrega al intersticio de la vida y la muerte entre las viejas luchas y la utópica revolución fallida. Como diría Nicolás Casullo (1994), las hogueras son el fracaso de la historia:

En Eva Perón en la hoguera nos enfrentamos ya a la ruina de un tiempo [...] nos encontramos con un texto de locura frente a los restos de la historia. Más precisamente, al desvarío de lo histórico cuando deja de protegernos con sus 'sentidos' y 'objetivos' a obedecer y a alcanzar la voz de Evita, en todo caso, es esa irrupción de la catástrofe de la historia [...] Nos saca del mito Evita, no para reponernos de aquella mujer revolucionaria la funcionalidad plástica de 
su cadáver, sino para sustraernos absolutamente de esa tentación (citado en Trombetta, 2014).

Por lo tanto, como advierte Nicolás Casullo, no podemos pensar que la Eva de Lamborghini sea un signo ya cerrado, una Eva-combativa. Desde nuestro punto de vista, es más productivo concebir a la operación lamborghiniana como una forma de sortear el signo-mitema Eva. Por lo tanto, creemos que el fuego podría ser pensado como ese crepitar constante que articula el ritmo de la poética de Lamborghini y reorganiza ética y políticamente la sintaxis de La razón de mi vida. La hoguera es el momento de la metamorfosis y transmutación. Ante esta cuestión, González advierte:

La metamorfosis labora con una materia pringosa que es su forma inasible, mutable y proteica [...] La metamorfosis es el reino de la mitología y es quizás el lugar en el que el pensamiento mítico mejor sostiene sus alcances [...] Por cierto, se trata de formas (2001, pp. 18-19).

Por consiguiente, encontramos en este "laborar" la fuerza oculta que impulsa la creación de la poesía y el mito. En la poesía lamborghiniana este "dar forma" depende de la dimensión de la escucha de esa tonalidad popular, las modulaciones y balbuceos de aquellos que solicitan salir de su indecibilidad. Como señala Ana Porrúa "el poeta es aquel que no tiene voz pero que da forma al lenguaje con las voces de los otros" (2001, p. 28). Pero esa poiesis solo es posible si el poeta parte por poner el oído en la sintaxis para, desde dentro, deshacer la alianza de sentidos que reifican los signos 
dominantes y lo convierten en Modelos. En palabras de Lamborghini:

No hay tangenciación con el modelo, sino intrusión violenta en el mismo. No hay variación sino mutación. La idea es que todo sistema literario es una cadena de modelos y derivados, lo que a su vez se institucionalizan como Modelos [...] En la reescritura por intrusión el Modelo es llevado al caos originario, de modo de practicar una y otra vez con él las operaciones del azar (2010, p. 117).

II.

Pero también la hoguera es el lugar previo a la representación desde el cual la mujer mira al magma del lenguaje en su caos originario, lo semiótico como chora anterior a la simbolización, como espacio o dimensión rítmica, anárquica, de ruptura y articulación (Kristeva, 1984). De acuerdo con la autora, el chora no es una posición que representa algo para alguien (no es un signo), ni tampoco es una posición enunciativa (un significante), aun así subyace, en tanto que ritmo vocal o cinético, como condición de la significación. Así lo señala Julia Kristeva al comparar el chora con aquello que Mallarmé pensaba como "espacio femenino misterioso": "rítmico, sin ataduras, irreducible a su traducción verbal inteligible; es musical, anterior al juicio, pero restringido por una sola garantía: la sintaxis" (Kristeva, 1984, p. 29). ${ }^{3}$

\footnotetext{
${ }^{3}$ En el original: "Mallarme calls attention to the semiotic rhythm within language when he speaks of 'The Mystery in Literature' ('Le Mystere dans les lettres'). Indifferent to language, enigmatic and feminine, this space underlying the written is rhythmic,
} 
En el mismo sentido, para León Rozitchner (2011), si la lengua paterna es el logos ordenador del pensamiento racional adulto y funciona como ley de enunciación que determina los límites de lo decible, esta supone a una lengua anterior, la materna. La "lengua mater" es el equivalente al chora de Kristeva, una materia poética, originaria, que no distingue entre phoné y logos ni entre significante y significado. Pero, a diferencia de la autora búlgara, la lengua mater, en tanto que espacio de resonancia - del eco y la acentuación- es el lugar del afecto como comienzo de producción del sentido. Es esta producción primaria, previa al régimen del signo, lo que Rozitchner llama "materialidad ensoñada". Para el autor de Perón entre la sangre y el tiempo, al igual que en Kristeva, la lengua mater es hallada en la sintaxis y la rítmica del poema:

La palabra poética habla prolongando en nosotros la lengua materna: convierte en lengua viva una lengua que fue dada por muerta. Retornar al sentido aborigen para decir desde lo más hondo lo inaudito, tratar de actualizar el ensoñamiento de las primeras palabras de una lengua perdida en la misma lengua [...] la poesía abre nuevamente, para que florezca, la materialidad humana, ensoñada primera sin el cual el sentido mágico de la vivencia poética no existiría -y la vida cantante y sonante- tampoco (Rozitchner, 2011, pp. 22-23).

Para decirlo en otros términos, el chora o la lengua mater como ritmo, es interior al enunciado pero exterior al significante y funciona como fuerza de performatividad. Ante esta aclaración deberíamos preguntarnos entonces cómo se

unfettered, irreducible to its intelligible verbal translation; it is musical, antenor to judgment, but restrained by a single guarantee: syntax" (Kristeva, 1984, p. 29).

$N^{\circ} 13$. Segundo Semestre de 2020 
vincula el ritmo con el mito. La respuesta ya ha sido dada de manera implícita: si el mito, de acuerdo a la definición de LéviStrauss (1997), es estructura y acontecimiento, la política del ritmo tiene lugar en la contingencia acontecimental, allí donde se pone en juego la vida. Es en ese terreno de fuerzas en pugna en donde se disputa el sentido del mito, por lo tanto, sus alcances performativos. En este sentido, para Rozitchner la conjunción mitopoética reside en pensar el comienzo del sentido en acontecer afectivo ${ }^{4}$ y lo imaginario materno, es decir, en ese balbuceo primario que significa sin significante.

Esta noción de lenguaje materno o materialismo ensoñado nos permite vislumbrar los efectos que tiene la estrategia lamborghineana de la reescritura de La razón de mi vida. Al romper con la sintaxis, mediante el recurso del anacoluto o corte de tronche (como lo llamaba Leónidas Lamborghini), lo que emerge del lenguaje desgarrado es la voz y la fuerza propia de Eva que se escondía tras aquella fachada de madre-mártirsanta, y que eran en realidad los signos del discurso patriarcal. A continuación, compararemos fragmentos del texto originario de La razón de mi vida con fragmentos de su reescritura:

Creo que nací para la Revolución. He vivido siempre en libertad. Como los pájaros, siempre me gustó el aire libre del bosque. Ni siquiera he podido tolerar esa cierta

\footnotetext{
4 "Por afecto hay que entender las afecciones del cuerpo, con los que se aumenta o disminuye, se ayuda o se estorba, la potencia de actuar del cuerpo y, al mismo tiempo, las ideas de estas afecciones. No se piensa de otro modo si no se siente de otra manera, y para ello hay que resistir a la denigración de lo sensible. Si 'el afecto es el que contiene al sentido' y cuando pensamos no sentimos que se 'conmueve al cuerpo' nos perdemos 'la prolongación ensoñada del cuerpo materno que es el 'elemento' o el 'éter' que da sentido pleno al pensamiento aunque sea abstracto” (Sztulwark, 2015).
} 
esclavitud que es la vida en la casa paterna, o la vida en el pueblo natal... Muy temprano en la vida dejé mi hogar y mi pueblo, y desde entonces siempre he sido libre. He querido vivir por mi cuenta y he vivido por mi cuenta. Por eso no podré ser jamás funcionario, que es atarse a un sistema, encadenarse a la gran máquina del Estado y cumplir allí todos los días una función determinada. No. Yo quiero seguir siendo pájaro suelto en el bosque inmenso. Me gusta la libertad como le gusta al pueblo, y en eso como en ninguna otra cosa me reconozco pueblo (Perón, 2010, p. 117)

Y el juego del poeta:

no funcionario: pájaro. así lo he querido. la libertad:

yo siempre.

mi revolución: yo siempre. creo que nací para ...

así: pájaro suelto en un bosque. inmenso.

pájaro no encadenado. no a la gran máquina. no al estado. pájaro: no a sueldo. no funcionario.

pájaro: siempre me gustó. he querido vivir. creo que nací. (Lamborghini, 2011, p. 75)

\section{La razón de mi vida:}

Descamisados fueron todos los que estuvieron en la Plaza de Mayo el 17 de Octubre de 1945; los que cruzaron a nado el Riachuelo viniendo de Avellaneda, de la Boca y de la Provincia de Buenos Aires, los que en columnas alegres pero dispuestos a todo, incluso morir, desfilaron aquel día inolvidable por la Avenida de Mayo y por las diagonales que conducen a la Casa de Gobierno; hicieron callar a la oligarquía y a aquél que dijo ‘yo no soy Perón'; los que todo el día reclamaron a gritos la presencia del Líder ausente y prisionero; los que encendieron hogueras con los diarios de la prensa que se había vendido a un embajador extranjero por treinta dineros $; 0$ tal vez menos! ¡Todos los que 
estuvieron aquella noche en la Plaza de Mayo son descamisados! (Perón, 2010, pp. 84-85)

\section{La Eva lamborghineana:}

para mí los excluídos:

en primer lugar. para mí los que estuvieron. los que cruzaron

viniendo. los que en columnas alegres. los que dispuestos.

los que a todo. los que a morir. para mí los que en diagonales

avanzaron. los que hicieron callar. para mí los que todo el día

los que reclamaban. los que a gritos. los que encendieron:

los que hogueras.

para mí en primer lugar: todos los que: aquella noche.

para mí:

todos los que antes.

todos los que ahora.

todos los que mañana.

todos los que: hogueras.

los excluídos: ¡ellos son!

todos los que antes todos los que ahora todos los que mañana.

el amor de mí.

la esperanza de mí.

para mí el pueblo: ¡ellos son!

(Lamborghini, 2011, pp. 69 y 70).

Como vemos en estos versos, mediante las variaciones y distorsiones, hay un desplazamiento del significante "Perón", así como un espacio entreabierto que las mismas rupturas sintácticas producen. Como un dejar decir que aún no se decide a aparecer, y que hace de esta ausencia-presente una 
potencia que motoriza la lengua a fuerza de repetición: el vacío que suscita la repetición del adverbio de negación "no" o el de cantidad "todos"; la insistencia de sustantivos como "pájaro", "fundamental", "causa", "sentimiento". Mediante esta estrategia, Lamborghini arranca del cuerpo de La razón de mi vida toda alusión al amor romántico de Eva y su subordinación a Perón. El rol de mediadora entre el pueblo y Perón, que se ve claramente en el texto original, se vuelve borroso como así también las referencias a la jerarquía de Perón-líder-cóndoraltura ante ella mujer humilde-gorrión-pueblo. Hay más bien un desplazamiento ascendente, una Eva que emerge. En este desplazamiento y articulación del ritmo poético, tanto el signoEva como el "organismo moral" del mito quedan abiertos al por-venir y por eso inacabados. ${ }^{5}$

Lo que puede un cuerpo en la poesía lamborghiniana está puesto en juego en esa relación entre signo y ritmo, como se percibe en el efecto del jadeo de El solicitante descolocado (2008) o la voz agónica, entrecortada, de Eva. En Mezcolanz̧as, Lamborghini afirma que lo que impulsa su proceso de escritura poética es una fuerza con la que tiene que negociar para darle forma. La apuesta está en romper el cliché del estereotipo encorsetado y liberar las palabras de esas exigencias del Modelo mediante la reescritura, para que tengan una potencia revolucionaria (Lamborghini, 2010).

\footnotetext{
${ }^{5}$ Hay innegablemente en esta política del ritmo una suerte de erotismo sexual al cual Lamborghini no rehúye, en sus reescrituras hay "penetración”, y juega con esta metáfora sexual, metiéndose en el canon de la cultura para abrir, gozar y dar vida a las palabras moribundas. Ver: El genio de nuestra raza, p. 125.
} 
Por lo tanto, pensar el ritmo es, en términos de Meschonnic (2007), articular el cuerpo al lenguaje: vivir-lenguaje. Y a su vez, esto se produce incorporando la oralidad que todo discurso esconde en su chora, y dando cuenta del dominio del signo. Esta actividad se vuelve, para Meschonnic, una ética y una política. Y esta política de la crítica del ritmo es la que supone el pensar lo poético como historicidad. En este sentido, la reescritura como política del ritmo, hace aparecer el vínculo entre el signo y lo teológico (el lenguaje patriarcal para Rozitchner) del "organismo moral" La razón de mi vida, y al hacerlo, lo desacraliza.

Es por esto que podemos ver en estos versos, lo que Ana Porrúa llama el movimiento de desacralización poética: "el borramiento de las causas que bordean lo sagrado será a la vez una conversión laica y una materialización del discurso político que no está presente en La razón de mi vida" (2001, p. 37). ${ }^{6}$ Por este motivo, creemos que es interesante pensar esta la reescritura y sus efectos desacralizadores como una estrategia de descentramiento de los fundamentos teológicos de todo signo. Como dice Henri Meschonnic, "la poética ya no es la estilística como tampoco lo es la crítica literaria [...] es el reconocimiento de su modo de significar, de su historicidad, y el examen de sus propios conceptos obrando en la lectura de una obra" (2007, p. 194). La poética misma empieza por la

\footnotetext{
${ }^{6}$ No podemos negar que esta táctica sobre la organización gramatical puede verse como una forma de resignificación de la figura de Eva desde la izquierda peronista, si entendemos a la lucha por la significación como lucha por la hegemonía en términos laclaucianos (Laclau, 2005). Este análisis es completamente válido, no obstante intentaremos bordear esta discusión, ya que permanece en el terreno del significante.
} 
escucha de ese "encabalgamiento de voces" (Porrúa, 2001) lamborghineano que forman del ritmo y en sus anacolutos que detonan los signos, materialidad que rehúye a la representación. La significación emerge en el reordenamiento del ritmo junto con los significantes. Por lo tanto, podríamos afirmar que existe un vínculo solidario entre el mito y la poesía, siendo esta última una suerte de salvaguarda de reactualización y rehistorización del mito para volverlo reparador y movilizante, a la vez que permite resituar el cuerpo, como afecto, en el discurso.

\section{Consideraciones Finales}

Por lo tanto, y para concluir, en estas líneas nos hemos propuesto abordar la reescritura Eva Perón en la hoguera atendiendo la tensión que el trabajo lamborghineano expone entre la búsqueda de historicidad (pensamiento poético), y el Modelo (mitema) de Eva madre-mártir-santa. En otras palabras, el objetivo fue explorar la dimensión conflictiva que la reescritura hace visible entre lo inmóvil del texto dogmático escolar, las hogueras del lenguaje, las luchas por la significación al interior del mito peronista.

Es por ello que partimos por pensar la máquina lamborguineana de la reescritura como deformación y reinvención, metamorfosis del ritmo que no es más que una estrategia de dar vida al mito. Lamborghini expone el Modelo de madre-mártir-santa, su ordenamiento patriarcal alrededor del Signo-Perón-Líder, y juega al extremo con implosionarlo. 
$\mathrm{Al}$ hacerlo, la reescritura se vuelve un soporte que reactualiza el mito desde el ritmo y logra dotarlo de nuevos horizontes de significación, por lo tanto, de movilización. En este experimento sobre la materia lenguaje que hace el poeta como mito destructor/solicitante, emerge el ritmo-Eva como una particular forma de vivir y resistir políticamente: "se trata del aluvión: penetrar en las 'fuentes' de la cultura y de las representaciones identitarias y 'meter las patas' ahí, transgrediendo todo tipo de tabúes [...] para hacerlas estallar y devolverle su carácter vital a la poesía" (Jorge, 2011 citado en Lamborghini, 2011, p. 121).

\section{Referencias Bibliográficas}

Althusser, L. (2005). La filosofía como arma de la revolución. Madrid: Siglo XXI. Sur

Astrada, C. (1964). El mito gaucho. Buenos Aires: Cruz del

Barthes, R. (2014). Mitologías. Buenos Aires: Siglo XXI.

Borges, J. (2012). El otro, el mismo. Buenos Aires: Editorial Debolsillo.

Derrida, J. (1998). Márgenes de la filosofía. Madrid: Cátedra.

Donnatouni Moratto, M. (2009) "La metafísica nacional de Carlos Astrada y la tercera posición". Revista de filosofía y Teoría Política, Universidad de La Plata. http://www.memoria.fahce.unlp.edu.ar/art_revistas/pr.3907/p r.3907.pdf

Ferràs, G. (2007) "Filosofía, mito y nación en Prometeo de Leopoldo Lugones". Anuario de Filosofía Argentina $y$ 
Americana,

http://bdigital.uncu.edu.ar/objetos_digitales/3444/ferrascuyo2 4.pdf

Friedemberg, D. (1999). "Herencias y Cortes. Poética de Lamborghini y Gelman”, Historia crítica de la literatura argentina, Noé Jitrik y Susana Cella (dir), Volumen 10, «Poéticas», Buenos Aires: Emecé.

Fondebrider, J. (1994). Conversaciones con la poesía argentina. Buenos Aires: Libros de Tierra Firme.

González, H. (2001). La crisálida: metamorfosis y dialéctica. Buenos Aires: Colihue.

---. (2008) Perón, reflejos de una vida. Buenos Aires: Colihue.

---. (2008) Kirchnerismo: una controversia cultural. Buenos Aires: Colihue.

Gramsci, A. (1993) La política y el Estado Moderno. Madrid: Planeta Agostini.

Grimber Pla, V. (2013). Eva Perón: cuerpo, género, nación: estudio crítico de sus representaciones en la literatura, el cine $y$ el discurso académico desde 1951 hasta le actualidad. Costa Rica: Editorial UCR.

Heidegger, M. (1992). Arte y Poesía. Buenos Aires: Fondo de Cultura Económica.

Lalcau, E. (2005.) La razón populista. Buenos Aires: Fondo de Cultura Económica.

Lamborghini, L. (2006, 14 de diciembre) "El poeta es alguien que le roba palabras al silencio”, S. Freira, Página 12. https://www.pagina12.com.ar/diario/suplementos/espectaculos /4-4794-2006-12-14.html

---.(2008) El solicitante descolocado. Buenos Aires: Paradiso.

---. (2010) Mezcolanzas. Buenos Aires: Emecé.

---. (2011) El genio de nuestra raza. Buenos Aires: Staton. 
Lévi-Strauss, C. (1997) El pensamiento salvaje. Bogotá: Fondo de Cultura Económica.

Mariátegui, J. (1987) El alma matinal y otras estaciones del hombre de hoy. Perú: Amauta S.A

Meschonnic, H. (2007) La poética como crítica del sentido. Buenos Aires: Mármol Izquierdo.

Perón, E. (2010) La razón de mi vida. Buenos Aires: Buro Editor.

Porrúa, A. (2001) Variaciones vanguardistas: la poética de Leónidas Lamborghini. Rosario: Beatriz Viterbo.

Prieto, M. (2008) Breve historia de la literatura argentina. Buenos Aires: Taurus.

Sorel, J. (1979) Reflexiones sobre la violencia. Buenos Aires: La Pléyade.

Sztulwark, D. (2015) "Poema y política en León Rozitchner". Blog Lobo suelto. http://anarquiacoronada.blogspot.com.ar/2015/o1/poema-ypolitica-en-leon-rozitchner.html

Trombetta, J. (2014). "La muerte fantasmagórica en las representaciones de Eva Perón en el cine y en el teatro", Revista Cena, 15, Universidad Federal de Rio Grande do Sur. https://seer.ufrgs.br/cena/article/view/49646

Vattimo, G. (1992). Más allá del sujeto. Nietzsche, Heidegger y la hermenéutica. Barcelona: Paidós.

Fecha de recepción: 15/11/20

Fecha de aceptación: 10/12/20 